\title{
El entramado de la Historia Oral
}

\section{The Framework of Oral History}

\author{
BIANCA RAMÍREZ RIVERA \\ Instituto de Investigaciones Dr. José María Luis Mora \\ México \\ correo: bpramirezr@gmail.com \\ ORCID 0000-0002-7555-3705
}

DOI I0.48I 02/hyg.vi54.248

Artículo recibido: 30/06/2019

Artículo aceptado: I3/o9/20 I 9

Garay Arellano, Graciela de y Jorge Eduardo Aceves Lozano (coords.). Entrevistar ipara qué?: múltiples escuchas diversos cuadrantes, Ciudad de México, Instituto de Investigaciones Dr. José María Luis Mora, 2017, 446 pp.

Cualquiera que se haya detenido un momento para apreciar el intrincado y bello trabajo puesto en la elaboración de un tejido, con seguridad ha experimentado el enorme placer de admirar, tanto con la vista como con el tacto, una obra de esta naturaleza: la maravilla de la forma y composición del entramado, las texturas, la diversidad de los colores, las figuras que se realizan o el tipo de hilado. No obstante, el espectador pocas ocasiones tendrá la oportunidad de presenciar de cerca el proceso de hechura, de contar con tiempo suficiente para observar cómo cada hebra se articula con la otra, o la creatividad, originalidad y habilidad de la artesana que lo urde.

Una situación similar ocurre con los lectores de algunas investigaciones en historia oral: la obra impacta en nuestros sentidos y pensamientos, sin saber de dónde provienen las fuentes orales, cómo 
es que han sido producidas o qué ocurrió en el encuentro entre entrevistado y entrevistador. Sin embargo, a través del libro Entrevistar ¿para qué?: múltiples escuchas desde diversos cuadrantes, no sólo es posible conocer la composición de diferentes investigaciones de dicha índole, sino también presenciar desde el taller la creación del producto.

Al desovillar las páginas de esta obra conjunta, uno cae en cuenta que, como se nos adelanta en la "Introducción", se trata de un texto provocativo y novedoso (p. 7), pues invita y guía al lector a contemplar visiones menos exploradas de eventos, movimientos o actores de la historia reciente de México y América Latina, al mismo tiempo que nos propone mirar desde una nueva óptica las múltiples posibilidades que existen para elaborar investigaciones de y con la historia oral.

El libro está compuesto por tres secciones. La primera de ellas, "Aproximaciones teórico-metodológicas", inicia con el trabajo de Perla Chinchilla Pawling, "La historia oral y las formas discursivas", en el cual la autora propone desentrańar la identidad de la historia oral a través de la recepción que el lector o público tenga de sus hallazgos. Asimismo, en la búsqueda de su esencia se plantea que, con la categoría de forma-discursiva, será posible "clarificar nuestras expectativas sobre todas y cada una de las diversas y ricas funciones que hoy ofrece la historia oral" (p. 52).

Por su parte, Jorge E. Aceves Lozano, en "La historia oral y su praxis actual: recursos metodológicos, estrategia analítica y toma de decisiones", postula que quien inicia una investigación en historia oral partirá en busca de nuevos derroteros, pero debe ser consciente de que transitará por caminos ya recorridos, los cuales deberá valorar, comprender y criticar constructivamente (p. 69). Anudado al texto que nos ocupa, Graciela de Garay, en "De la palabra a la escucha. Una reflexión sobre la legitimidad del testimonio de historia oral”, llama la atención sobre un elemento que pudiese pensarse que existirá por descontado en este tipo de trabajos, pero sobre el cual es necesario reflexionar: para quien entrevista, es fundamental la escucha atenta, pues sólo así será posible acercarse de manera fidedigna a las vivencias, experiencias o puntos de vista de los entrevistados. De esa manera, de Garay sostiene un punto que no tendría que ser válido en exclusiva 
para la historia oral, sino para las ciencias sociales y humanidades en su conjunto, es decir: "que la escucha es imprescindible para superar la indiferencia, la marginación y el autoritarismo. La escucha implica que las partes se reconozcan una a la otra como legítimas y dignas de confianza para establecer una comunicación dialógica” (p. 104).

El último trabajo del bloque es de la autoría de Sara Makowski Muchnik, y con el título "Por una escucha de lo inaudible social. Arqueologías y tácticas" propone escuchar a sujetos excluidos de la sociedad, con el objetivo de dar cuerpo e identidad a quienes han sido arrojado a los márgenes de la sociedad. De acuerdo con la autora, aunado a la escucha, es necesario reconocer histórica y socialmente al otro, comprometerse con él y ser hospitalario (pp. 144-145).

La segunda sección del libro, "Sobre la memoria y la escritura de la historia”, versa sobre la relación, fundamental y nunca ausente de conflictos, entre la memoria y la historia. Tres ideas provocadoras surgen de la lectura de estos trabajos. La primera de ellas se encuentra en el trabajo de Marta Philp, "La fuerza de lo diverso: fuentes escritas, orales y audiovisuales para la investigación de los procesos de legitimación política”, donde se llama a comprender los matices sutiles y las nuevas fuentes -entre ellas la historia oral- con que la historia del tiempo presente y el entendimiento que tenemos de ésta se entreteje; todo ello con el objetivo de que la historia no sea "un recurso de unos pocos sino como derecho de la mayoría o al menos de todos los interesados en ejercer su deber de memoria" (p. 167).

Por su parte, en "Memoria de los movimientos sociales: una propuesta de análisis”, de la autoría de Mario Camarena Ocampo y Rocío Martínez Guzmán, se plasma que si bien es usual pensar que miembros de determinadas colectividades tendrán opiniones o visiones del mundo abrumadoramente similares, en este trabajo es posible observar, desde el interior de una colectividad, cuán divergentes pueden llegar a ser las voces de un mismo movimiento y cómo es que éstas se integran en la memoria colectiva del mismo para continuar funcionando como grupo (p. 176). La historia oral se plantea entonces como herramienta de investigación, pues sólo a través de las pautas de intercambio que ofrece, se podrá absorber la visión indivi- 
dualizada que el relato de una persona tiene, y cómo éste se integra al que el resto del grupo tiene por separado y como conjunto.

Por último, en "Crónica de una infidelidad. Cavilaciones y decisiones desde el taller del historiador", Claudia Canales Ucha insta a que se discuta sobre uno de los obstáculos más comunes que debe superar todo aquel que se acerca a las fuentes orales: ¿cómo plasmar en el papel lo que de forma tan natural se produjo en la narración hablada? La autora anota que de modo inevitable el investigador será infiel a la palabra del narrador, mas no a su esencia: la selección y edición no tendrá otro propósito que "volver accesibles, a quienes nunca escucharon al entrevistado de viva voz, toda la sustancia y acaso también buena parte de la emoción de su testimonio" (p. 194).

Si los primeros dos bloques funcionaron a manera de manual sobre cómo construir nuestro propio telar, la última sección se constituye como muestrario de la rica gama de telas que se han tejido y cuyos patrones es posible seguir. Así, "Experiencias empíricas" abre con el capítulo de Rodrigo Laguarda titulado "La Virgen de Guadalupe. Apropiación gay de la madre amorosa”. En este trabajo el autor nos muestra, a través de once entrevistas realizadas a mexicanos que se identifican como homosexuales, que es posible "mantener unida, mediante la imagen guadalupana, su identidad sexual, religiosa y nacional” (p. 223). Con el texto de Laguarda, se puede observar cómo los individuos pueden optar por la fusión de adscripciones sociales que, en sentido estricto, se conflictuarían una con la otra.

Enlazado a este trabajo sobre la identidad se encuentra "La lucha de un sindicalista: una historia oral" de Patricia Pensado Leglise. A partir del relato de Carlos Sánchez, trabajador emblemático del Sindicato Único de Trabajadores de la Industria Nuclear (sUTiN), la autora nos ofrece un acercamiento a la vida político-sindical de dicha organización, al mismo tiempo que contextualiza cómo la experiencia de Carlos está permeada por una nueva forma de relación del Estado con las organizaciones de este tipo, producto del neoliberalismo (p. 244). El planteamiento de Pensado Leglise se muestra como una de las propuestas clásicas de la historia oral, es decir: comprender, a través del relato personal, el horizonte histórico, político y cultural de 
un periodo concreto, al tiempo que se establecerán las implicaciones que el contexto colectivo tuvo en la experiencia individual.

Por su parte, el texto "Megaproyectos e historia oral: algunas lecciones del proyecto hidroeléctrico Zimapán, veinticinco años después”, de Juan Carlos Domínguez y Jimena Chávez nos muestran cómo la historia oral es una herramienta privilegiada para contrastar la retórica de un Estado que pugna por el desarrollo nacional, con la experiencia que dicha búsqueda tiene en las comunidades impactadas (p. 248). Al escuchar cuáles son las implicaciones en las esferas culturales vitales para el bienestar de una comunidad, los autores proponen comprender que, dentro de todo proyecto de esta naturaleza, yacen las voces de implicados a los que pudiera ignorarse, y las cuales aportarán elementos de análisis que no son fácilmente aprehensibles ni cuantificables desde las metodologías tradicionales de evaluación de proyectos.

El cuarto capítulo de esta sección, “T'Tú eres recordar’: La historia oral y el estudio del proceso migratorio contemporáneo”, de Leticia Calderón Chelius, señala la importancia que la historia oral tiene para la comprensión de la movilidad humana internacional. A través del relato personal, se conocerá un fragmento de una historia social de alcances globales que "más allá de nostalgia, la ausencia, la distancia emocional, [mostrará] un proceso de confrontación y contraste de valores, gustos, prácticas y vivencias que tienen un impacto directo en el propio sujeto, pero también sobre la sociedad de origen y de destino" (p. 248).

El siguiente capítulo, titulado "Imágenes, voces y experiencias de y con la discapacidad en México", de María Concepción Martínez Ocaña, emplea a la historia oral como dispositivo para comprender la disputa entre las imágenes públicas sobre la discapacidad y la participación que las personas discapacitadas tendrán en la reelaboración de las concepciones que se tienen acerca de sus experiencias de vida. De esa manera, se plantea que sólo al comprender que la discapacidad es una condición única y singular (p. 327) en la vida de algunas personas, se podrá plantear la integración de una identidad común que no recurra a la homogeneización de los individuos. 
En "Testimonios de los años de la guerra: un diplomático mexicano en Nicaragua y El Salvador, 1978-1981”, de Mónica Toussaint, la autora hila fragmentos del testimonio del embajador Gustavo Iruegas en los que se pone en evidencia cómo en la política exterior mexicana de aquel momento se entrelazaron tanto una política de Estado interesada en participar activamente en la región, como la actuación de un funcionario progresista y proclive a apoyar a los movimientos revolucionarios en Centroamérica. Asumiendo la postura de que "todo testimonio tiene un sentido político, porque el relato de uno de los actores concretos de un proceso no puede ser ajeno al contexto en el que se desarrolla" (p. 363), la autora nos permite explorar entre los contrastes de la posición personal radical de un funcionario y los desafíos que representó un sistema que navegaba entre la inflexibilidad y la permisividad.

Los últimos dos capítulos emprenden una visita al Cono Sur latinoamericano. El primero de ellos es de la autoría de Araceli Leal Castillo. En "Los caminos de la jurisdicción universal: la extradición del represor argentino Ricardo Miguel Cavallo", el objetivo planteado es reconstruir la memoria colectiva sobre la paradigmática extradición a España del torturador argentino, resaltando las diversas acciones que realizaron los exiliados argentinos en México, en España y en otras partes del globo. Si bien Leal Castillo no participó en la elaboración de los testimonios orales (p. 393), su trabajo nos ofrece una óptica y una posibilidad más dentro de la historia oral, es decir, la del analista que a pesar de no estar presente en el encuentro donde nace el relato, se sumergirá en un proceso de riguroso análisis e interpretación de las fuentes orales.

La tercera sección y el libro cierran con el capítulo de Silvia Dutrénit y César Tcach titulado "Fuentes Orales y represión política: antes y después de la ciencia”. En este trabajo conjunto, los autores señalan el momento coyuntural en que se encuentran las sociedades en búsqueda de Verdad y Justicia, pues se trata de un lapso en el que los procedimientos y pruebas científicas están situados en el centro de la discusión. En ese sentido, el predominio de la ciencia y sus métodos acompañarán los procesos de rememoración para saber qué fue 
lo que aconteció, cómo aconteció y quiénes fueron los responsables de violaciones a derechos humanos en el contexto de las dictaduras de seguridad nacional en América Latina. En un presente que los autores llaman de posmemoria, el interés de las fuentes orales recae en "alcanzar el más alto grado de verdad posible. Se trata de corregir presunciones, pulir hipótesis, sustentar o descartar con evidencias empíricas intuiciones, sospechas e indicios casi siempre fragmentarios" (p. 419).

Si bien el libro no es el primero que ambos coordinadores publican en torno al estudio de la historia oral, la importancia de éste radica en que ofrece una visión panorámica de las competencias y posibilidades de las fuentes orales. En ese sentido, esta obra permitirá al lector indagar sobre la práctica de la historia oral como metodología, como disciplina o como herramienta auxiliar, y sin discusión le servirá como palco privilegiado para verla en acción en la investigación social desde una diversidad inimaginable de ópticas y temáticas.

Cada capítulo de Entrevistar ¿para qué?: múltiples escuchas desde diferentes cuadrantes no funcionará como hebras individuales del tejido que captó nuestra atención. Por el contrario, cada estudio representará un entramado especial elaborado en el telar de la historia oral, y donde el lector será partícipe del proceso de urdimbre, conocerá con qué filamentos se conformó el diseño y qué puntadas fueron las necesarias; es decir, podrá acercarse a los procesos de entrevista, las experiencias de cada investigador, e inclusive saber desde dónde se escucha, qué es lo que se pregunta y cómo se pregunta. Finalmente, es importante subrayar que este libro brinda un cúmulo importante de herramientas teóricas y prácticas que podrán ser empleadas en nuevas investigaciones, al mismo tiempo que muestra cuán necesarias son las rigurosidades epistémica y metodológica, así como las dimensiones ética y política que confluyen en el telar de la historia oral. 医 